\title{
Fracking on YouTube: Exploring risks, benefits and human values
}

\author{
Rusi Jaspal \\ De Montfort University, UK \\ Andrew Turner \\ University of Leicester, UK \\ Brigitte Nerlich \\ University of Nottingham, UK
}

Fracking or the extraction of shale gas through hydraulic fracturing of rock has become a contested topic, especially in the United States, where it has been deployed on a large scale, and in Europe where it is still largely speculative. Research is beginning to investigate the environmental and economic costs and benefits as well as public perceptions of this new energy technology. However, so far the social and psychological impact of fracking on those involved in it, such as gas workers, or those living in the vicinity of fracking sites, has escaped the attention of the social science research community. In this article we begin to fill this gap through a small-scale thematic analysis of representations of fracking in 50 YouTube videos, where a trailer of a controversial film, Gasland (Fox, 2010), has had a marked impact. Results show that the videos discuss not only environmental and economic costs and benefits of fracking but also social and psychological impacts on individuals and communities. These videos reveal a human face of fracking that remains all too often hidden from view.

\section{Acknowledgements}

We would like to thank the ESRC for their financial support of project RES-360-250068 and the University of Nottingham for additional financial support.

\section{Contact}

Dr Rusi Jaspal, School of Applied Social Sciences, Faculty of Health and Life Sciences, De Montfort University, Leicester LE1-9BH, United Kingdom. E-mail: rusi.jaspal@gmail.com 
Some of the most pressing problems facing governments all over the world include climate change and resource depletion, in particular of fresh water, soil and, of course, fossil fuels. This has led to efforts to reduce $\mathrm{CO}_{2}$ emissions, on the one hand, in order to mitigate the effects of global warming, and to search for novel sources of fossil fuels, on the other.

One of these novel sources of fossil fuel is shale gas, which is extracted from the earth by hydraulic fracturing or "fracking" involving the use of water, sand and chemicals. Induced hydraulic fracturing is the process whereby high-pressure water with additives is used to increase fissures in the shale rock layer and thereby extract natural gas embedded within the layer (for a more detailed description, see The Royal Society and The Royal Academy of Engineering, 2012). Shale gas is a natural gas and therefore often claimed to have a lower carbon footprint compared to traditional fossil fuels (Engelder, 2011). As a result, it is sometimes positioned as a clean(er) or 'transitional' energy source and argued to contribute to climate change mitigation. However, debates are emerging about the threat posed by fracking to water resources (Finewood and Stroup, 2012), about large-scale methane leakage (Slezak, 2012), and also about fracking as a distraction from efforts to reduce the use of fossil fuels and from investing in alternative energy sources. Despite this, fracking has become a boom industry in the United States. In the UK, fracking has been attempted on a small scale but came to a halt after it was linked to some small earthquakes (Jaspal and Nerlich, in press a). It is now back on the agenda after the government lifted a moratorium in December 2012.

Fracking has as yet not been studied in detail by social scientists, ethicists and experts in science and technology studies. There has been some recent work on the politics and regulation of fracking, particularly in the US (Forbis and Kear, 2011; Mooney, 2011; Negro, 2012). However, this has not yet been matched by detailed research into public perceptions of fracking and in particular the social and psychological dimensions of fracking. This article begins to address this gap in research by examining (i) portrayals of the risks and benefits of fracking, with particular attention to the human dimension of fracking; and (ii) how fracking might affect environmental values and, consequently, the identities of individuals and communities directly involved in fracking, as reflected in a small number of YouTube videos on fracking.

Given the importance of social media in the debate on environmental issues (Jaspal, Nerlich and Koteyko, 2013; Porter and Hellsten, in press), this article examines the role of high-impact YouTube videos in constructing narratives of fracking, both in terms of their risks and benefits and their implications for environmental values and identity, which could in turn shape public understanding of the technology.

\section{The human dimension of fracking}

Some research into the human dimension of fracking is emerging in the UK and the US. One research project at the University of Durham ${ }^{i}$ has studied the perceived impacts of fracking across Europe and found that concerns were very much shared across countries, in particular around issues of water contamination, seismicity, waste water and water usage, subsidence, long-term fate of fracking fluid, changes in subsurface pressure regime, impact on landscape, and fugitive emissions. The focus here seems to have been on exploring economic and environmental values. In particular, there is an argument that intrinsic environmental values (surrounding water, landscape etc) are potentially threatened by the practice of fracking (Callicott, 
1986; Elliot, 1992).

A different focus can be found in a study of public attitudes carried out by Nick Pidgeon at the University of Cardiff. His research, which used deliberative workshops, found that people tend not to view fracking as a solution to either the energy crisis or climate change. Pidgeon stresses that "[o]nly focusing on the engineering concepts of risk - probabilities, damage estimates etc - is unlikely to meet people's actual concerns about fracking" and that "[r] isk communication must aim for a genuine dialogue with the affected public, and one that aims to build trust through exploring people's different values, and meeting their concerns about uncertainty or governance arrangements." (ESRC, 2012) Here the issue of values emerges in the context of a public dialogue about fracking.

A survey-based report into public perceptions of fracking in the UK was carried out at the University of Nottingham in 2012 (O'Hara et al., 2012) and is repeated every six month. It found in 2012 that in the UK public opinion on the question is as yet unformed or highly uncertain and that "overall, shale gas appears to be a fuel source over which the public has yet to make up its mind" (O'Hara et al, 2012: 10). Attitudes seem to be shifting towards more acceptance in 2013 (O'Hara et al, 2013).

O'Hara et al. (2012) show that most of the British people surveyed in their research mention television news (and other audiovisual sources) as primary sources of information concerning fracking (and therefore as a way to 'make up their minds'). However, for those seeking additional information independent of any viewing schedule, YouTube videos may also be of importance, especially since a documentary film made in the United States, Gasland, became a focus for debate after 2010 and was also discussed in the traditional press (Jaspal and Nerlich, in press b).

Gasland is mentioned 131 times in UK newspapers since September 2010 and out of 94 BBC news items, five mentioned Gasland. Similarly, it has been argued that YouTube (and the comments that YouTube generates) constitutes an important social context for understanding public understandings of climate change and its mitigation technologies (Porter and Hellsten, in press). Moreover in the medical literature the content of YouTube videos has been used as a data source for understandings of, for example, vaccination (Keelan, Pavri-Garcia, Tomlinson and Wilson, 2007), tobacco use (Freeman \& Chapman, 2007) and bird flu (Pandey, Patni, Singh, Sood and Singh, 2010).

When surveying YouTube videos on fracking we noted that many were produced in the US and dealt not only with general risks and benefits of fracking but also, and even more so with the social and psychological impact on fracking in a country where fracking is already a reality. In general, the videos make reference to intrinsic environmental values, in particular - the notion that environmental phenomena (e.g. landscape, water, nature) should be valued by virtue of their very essence (Callicott, 1986; Elliot, 1992). Therefore, in this article, we focus largely upon intrinsic, rather than extrinsic, environmental values. We regarded the YouTube videos not only as a source for studying how public perceptions may be shaped by them, but also, and even more so, as a resource for studying how human, cultural and environmental values are discussed, that is to say how what one may call the human face of fracking is expressed in these short films. This became the focus of this article.

Such social and psychological impacts, especially social and community health risks of fracking are still rarely discussed by social scientists, but things seem to be gradually changing. For instance, Finewood and Stroup (2012) have examined the impact of fracking for water sources in Pennsylvania from the perspective of 
environmental values. The authors argue that "neoliberal pro-fracking arguments are (re)defining the relationship among people, the environment, and institutions, which in turn normalizes the impacts on communities and the resources on which they depend" (p. 72). The authors also "suggest that an analysis of fracking should include an investigation into the neoliberal-politicized strategies that various stakeholders and production firms use to define environmental resources, and the ways these efforts often benefit some, despite deleterious impacts on others and the places they live" ( $p$. 74). This clearly highlights the need for researchers to examine the role of environmental and human values in the debate about fracking in order to provide a more holistic account of the social and psychological implications of fracking.

In this paper we focus on narratives of risk and benefit communicated in YouTube videos which also focus on fracking's deleterious impacts on selves and others and the places they live in, that is, its impacts on values attached to places, communities and the individuals who inhabit them. This is consistent with research into place attachment and place identity in the context of novel energy sources and NIMBYism (Devine-Wright, 2009; Devine-Wright and Howes, 2010).

As the most viewed YouTube clip on fracking in November 2012 (when we carried out our study) was a Gasland trailer, we begin by providing some information about this important film. We then go on to describe the theoretical and methodological aspects of our study, followed by the results of our analysis. It should be stressed, however, that this is a small-scale and opportunistic study, which is intended to initiate further research and debate on the role of environmental and human values in fracking, as well as more detailed research into its social and psychological impacts.

\section{Gasland: A social "game-changer"}

In media reporting, fracking is frequently referred to as a "game changer" with regard to energy supply issues and climate change (Jaspal and Nerlich, in press b). The documentary film Gasland can be regarded as a 'game changer' when it comes to public debates about fracking. Gasland was produced in 2010 by Josh Fox and has become a major resource in the mobilisation against fracking (being followed more recently by the film Promised Land [van Sant, 2012]). Gasland focused quite explicitly on threats allegedly posed by fracking to intrinsic environmental values when it depicted the contamination of air, water and landscape. It was nominated in 2011 for an Academy Award for Best Documentary. This is how the film is described on its promotion website ${ }^{\text {ii. }}$
About the film
"The largest domestic natural gas drilling boom in history has swept across the United States. The Halliburton-developed drilling technology of "fracking" or hydraulic fracturing has unlocked a "Saudi Arabia of natural gas" just beneath us. But is fracking safe? When filmmaker Josh Fox is asked to lease his land for drilling, he embarks on a cross-country odyssey uncovering a trail of secrets, lies and contamination. A recently drilled nearby Pennsylvania town reports that residents are able to light their drinking water on fire. This is just one of the many absurd and astonishing revelations of a new country called GASLAND. Part verite travelogue, part expose, part mystery, part bluegrass banjo meltdown, part showdown."

Gasland had a direct impact on search patterns for fracking in the United States, as 
the following data from Google Insights for search show, where the film seems to have initiated a debate about fracking (see Figure 1):

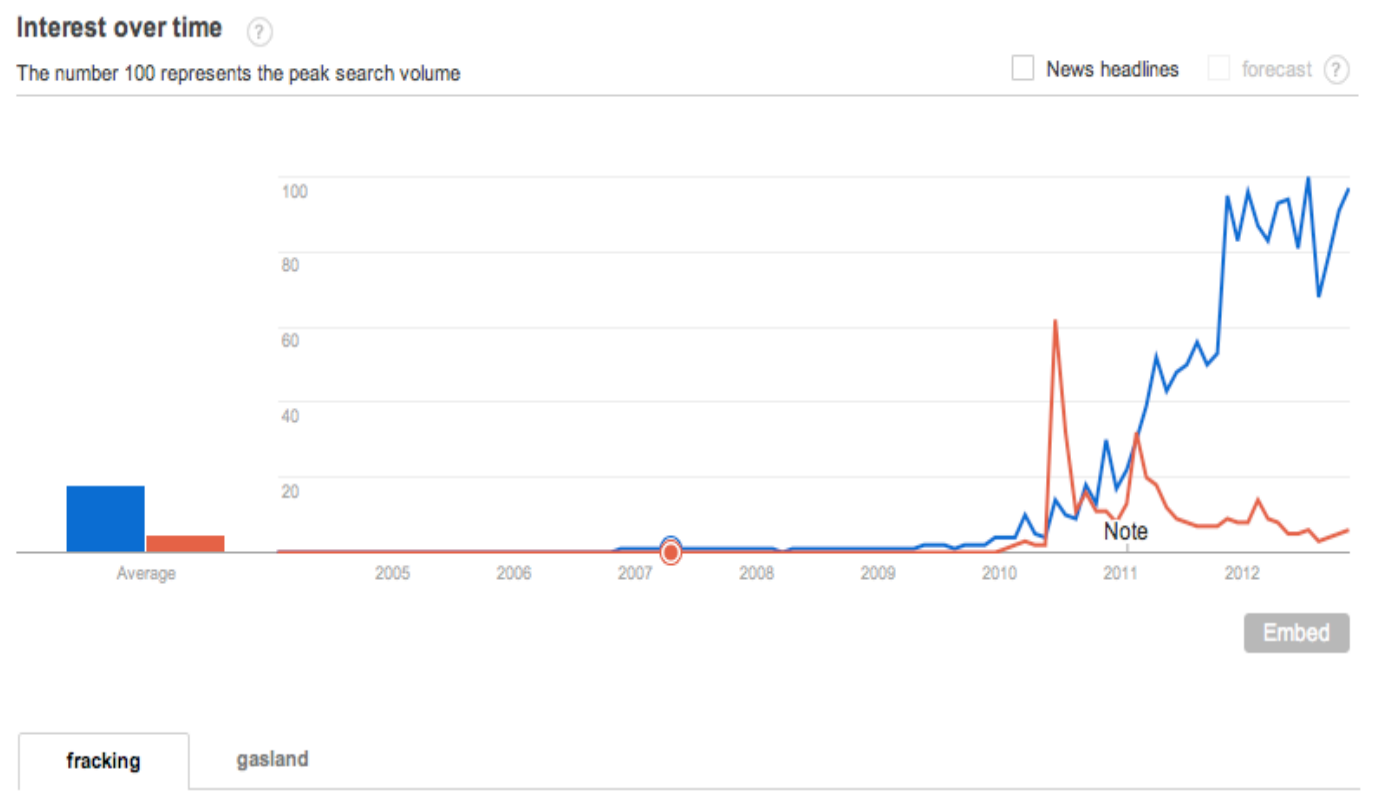

Figure 1: Google Insights, interest in the term "Gasland" (red) and "fracking" (blue) in the US since 2005

A trailer of Gasland on YouTube has attracted over 2 million views. However, this is not the only information that those searching for information on fracking can find on YouTube. There are many more videos out there that convey various messages about fracking, from a variety of perspectives and positions.

\section{METHOD}

In order to study the range of representations and arguments around fracking that can be found on YouTube, this study selected fifty YouTube videos and analysed them using qualitative thematic analysis and Identity Process Theory.

The fifty videos available on YouTube are a heterogeneous collection of videos about fracking that differed considerably in format and provenance. The sample included news-reports, documentaries, home-made videos and marketing material. The videos analysed share high popularity (in terms of view counts) on YouTube. The heterogeneity of the videos is an advantage for our analysis because it provides a rich source of data that illustrates the multiple and complex ways that environmental values, risk and benefits can interact and in turn be configured by different actors in the debate about fracking. Despite this heterogeneity, the YouTube videos we analysed all spoke to important debates about fracking and many included clips telling personal or what one might call 'human interest' stories.

It is noteworthy that the videos are mainly of US origin (the list of 50 includes three non-English-language videos, of those in English one is about Poland, the rest are all about US), but given YouTube's contribution to "cultural globalization" and international participatory culture (Lashley, 2012), it is likely that many of the representations observable in the US will be communicated to other parts of the world 
and set the agenda for public understanding.

\section{Theory and analytical approach}

Identity Process Theory provides an integrative and holistic model of the self and integrates distinct epistemological positions. In this article we attempt to apply aspects of the theory to the study of environmental and human values (Breakwell, 2010a), especially of the impact of fracking on the understanding of self, others and values attached to places and communities. Identity Process Theory (Breakwell, 1986, $2010 \mathrm{~b}$ ) argues that groups and individuals strive to maintain feelings of (1) continuity, (2) self-esteem, (3) self-efficacy, and (4) distinctiveness. Moreover, introducing a fifth principle, Jaspal and Cinnirella (2010) argue that coherence between identity elements is important. These principles may be regarded as cultural values in that they specify what is culturally desirable for identity, at both the individual and group levels (Lyons, 1996). These principles are likely to be culturally and temporally specific (Breakwell, 2010b). Thus, while human values are relatively stable, overarching goals in people's lives (Schwartz, 1992), identity principles are culturally desirable endstates for identity which are in flux. According to the theory, inappropriate levels of these "identity principles" can result in identity threat. Identity threat, in turn, can result in a number of "coping strategies," which often include deflection strategies and even political paralysis (Nerlich, 2010).

In this article, we do not focus on the psychological aspects of identity processes. Rather, we examine the constructed social, economic and environmental risks and benefits of fracking and the constructed outcomes for identity as specified in Identity Process Theory. Crucially, these constructed risks and benefits may affect the identity principles in a variety of different ways. For instance, a technology that may conceivably pose a "risk" to the environment may, conversely, bolster national selfefficacy by providing greater economic competence and control, while a constructed "benefit" in terms of employment could, nonetheless, be construed as a threat to continuity due to the scale of social change (Jaspal, Nerlich and Cinnirella, in press). Consequently, it is necessary to tease out the diverse human identity implications that the constructed risks and benefits of fracking can have. Identity Process Theory provides scope for integrating analyses of intrinsic environmental values and cultural values (e.g. continuity, distinctiveness and so on).

Recently, social psychologists (Coyle and Murtagh, 2013; Dixon, Durrheim and Di Masso, 2013) have made a convincing case for examining discursive constructions of identity threat - that is, how particular events and phenomena are represented as affecting continuity, self-efficacy and so on. This is important because constructions of identity threat may become reified in public understanding of controversial technologies and can provide a persistent lens for viewing and construing the potential implications of adopting them (Devine-Wright, 2009). As a social constructivist theory (Jaspal, 2013), Identity Process Theory can be fruitfully applied to studies in psychology and the humanities. Accordingly, in this paper, we invoke tenets of the theory, as a heuristic lens, in order to understand the negative and positive portrayals of fracking and how they are used in order to construct particular social and psychological outcomes.

Thematic analysis has been described as "a method for identifying, analysing and reporting patterns (themes) within data" (Braun and Clarke, 2006: 78). Here the method is employed in order to identify key themes and arguments used in our corpus of fifty YouTube videos. Our aim in this paper is to provide a rich thematic description of this relatively small corpus of videos, which is particularly useful given 
the dearth of research into the use of videos in the context of climate change communication (but see Porter and Hellsten, in press). Our approach is based on variants of thematic analysis that have been employed to examine both textual and visual data (Nerlich and Jaspal, in press). We focus primarily upon the verbal accounts offered in the YouTube videos but also examined the audiovisual elements of the videos in order to establish the tone of the videos, for instance. This research suggests that thematic analysis can be used as an inductive approach whereby the themes are closely linked to the data themselves, and thus data-driven, rather than interpreted through the lens of any pre-existing theory (cf. Jaspal and Nerlich, in press a).

A key advantage of using thematic analysis lies in its ability to integrate the micro and macro levels of analysis. Indeed, our analysis "goes beyond the semantic content of the data [that is, the micro level], and starts to identify [...] the underlying ideas, assumptions and conceptualizations - and ideologies - [that is, the macro level] that are theorized as shaping or informing the semantic content of the data" (Braun and Clarke, 2006: 84). Accordingly, we identify how particular micro-level constructions resonate with macro-level representations which circulate in social discourse. For instance, the micro-level use of negative metaphors in describing the impact of fracking for the landscape was mapped onto the cultural value of continuity (a macro-level phenomenon), in order to discern potential relationships between micro-level language and macro-level cultural values. It is widely acknowledged that the interpretative framework of the analyst is key in qualitative thematic analysis, which has led to criticisms of excessive subjectivity in qualitative research and to debates about quality control in the qualitative paradigm (Stiles, 1999). In order to address this limitation, the authors discussed potentially idiosyncratic interpretations of the data until consensus was reached.

\section{Procedure}

YouTube was searched using the terms "fracking shale gas", which returned over 1000 results. The Uniform Resource Locators (URLs) of the 50 most viewed videos on YouTube were recorded, and then the videos were profiled (excluding duplicates and non-English language videos, this gave 43 videos). All URLs were recorded at a single point in time, as it was found that search results on YouTube were unstable and often changed (though it is unclear precisely what range of physical and virtual factors contributed to this instability). Initially we tabulated the videos by the number of views they attracted, summarised their content and noted the positive or negative tone adopted in the video, as the following screenshot of our excel spread sheet shows. 


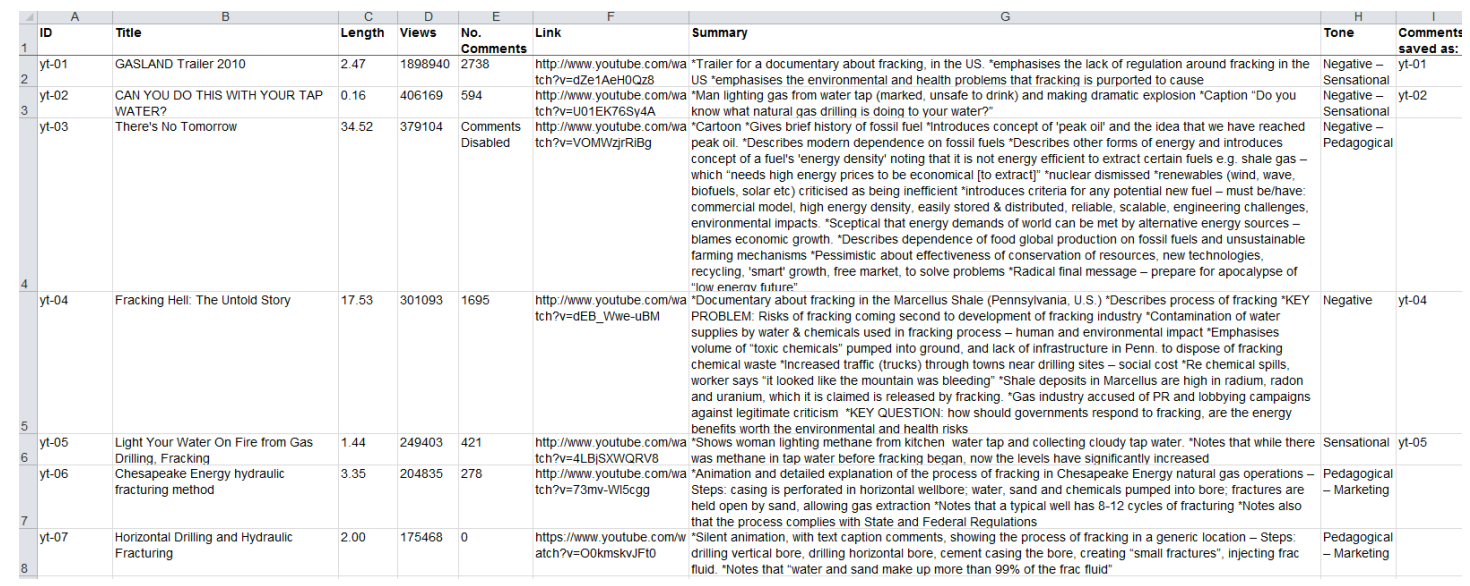

Figure 2: Illustration of coding procedure

The descriptive summaries were then used for a three-step thematic analysis, consisting of initial rough coding, including the tone of the videos, sorting and focusing in on thematic clusters for more in-depth analysis.

\section{Coding, sorting and tracking thematic clusters}

As one can see from the reproduction of our spreadsheet above (Figure 2), a large number of views does not necessarily translate into a large number of comments. Unsurprisingly, the Gasland trailer (yt-01) was the most viewed YouTube video and attracted the most comments (see Figure 3). The next most commented on video we could find (where comments were not disabled) was entitled 'Fracking Hell: The Untold Story' (yt-04), which is also featured on the web-site of the UK anti-fracking movement 'Frack-off', or the Extreme Energy Action Network. ${ }^{\text {iii }}$

\begin{tabular}{|l|l|}
\hline Video & No. Comments \\
\hline yt-01 & 2738 \\
\hline yt-04 & 1695 \\
\hline yt-02 & 594 \\
\hline yt-16 & 589 \\
\hline yt-22 & 444 \\
\hline
\end{tabular}

Figure 3: Number of comments on the YouTube Videos selected for this study

Off-shoots of the Gasland film included video clips entitled 'Can you do that with your tapwater?' (yt-02), 'Factory farming, fracking and 49ers' (yt-16) and 'The truth about fracking' (yt-22).

Compared to many other YouTube videos, some of which attract millions of views, the numbers of views for fracking videos are actually quite small. The viewing figures are, however, similar to those for other contested climate change mitigation technologies, for example, such as carbon capture and storage and geoengineering.

Within the 43 videos, five general styles of video were evident: (1) Newsreport, (2) Magazine or Documentary, (3) water-tap gas ignition, (4) Gas company 
marketing, (5) Other unique or unusual videos.

\begin{tabular}{|l|l|l|}
\hline Type & Frequency & Tone \\
\hline News-report & 5 & Mixed/neutral \\
\hline Magazine/Documentary & 9 & Mostly negative \\
\hline Water-tap gas ignition & 6 & Negative/sensational \\
\hline Gas company marketing & 12 & Wholly positive \\
\hline Others & 11 & Mostly negative \\
\hline
\end{tabular}

Table 1: Overview of type, frequency and tone of YouTube videos selected for this study

The top four most commented on videos were all negative in tone, highlighting environmental risks and or human costs over economic benefits. Equivalently, all videos with over 500 comments are negative. The large majority of positive videos, which focused on economic benefits, are marketing videos of gas companies, whereas the negative videos come from a wider range of sources.

A rough coding for major themes was carried out first, based on the description of the videos on the excel spread sheet. The resulting list of themes was discussed by the three co-authors and then sorted into two major thematic clusters around videos that were in favour of fracking and those opposed to fracking. It should be stressed that the numbers besides the themes indicate how often a theme was discussed in the videos, not the number of videos that we found for each theme. The final thematic categorisation is as follows:

Videos highlighting benefits and opportunities

(1) FRACKING BOOSTS THE ECONOMY

- Fracking jobs give people opportunity to realise "American dream" (2)

- Gas Companies concerned about regulation stifling growth (1)

(2) FRACKING IS SAFE

- Multiple layers of casing on the well-bore prevents ground pollution (8)

- Fracking is too deep in the ground for chemicals to pollute groundwater (4)

- Problems that have been reported are not problems with fracking per se (1)

- Fracking does not pollute the surrounding air/environment (1)

- There are no examples of groundwater pollution from fracking chemicals (1)

(3) FRACKING DOES NOT HARM THE ENVIRONMENT OR COMMUNITIES

- Fracking has less impact on the environment than conventional drilling (5)

- Gas companies are socially and environmentally responsible (4)

- Pro-fracking Geologist self-describes as an environmentalist (1)

- Residents near drilling sites are well-looked after by gas companies (1)

Videos highlighting risks and costs

(1) HUMAN COSTS

- Social cost of fracking work is tragic (5)

- Fracking causes the industrialisation of small towns [bad] (5)

- Housing gas industry workers is an industry in itself (5)

(2) ENVIRONMENTAL COSTS

- Environmental cost of fracking is tragic (2) 
- Fracking pollutes the surrounding air/environment (6)

- Fracking contaminates groundwater ((4)

- Natural gas not a cleaner replacement for oil (1)

- Fracking puts added pressure on water resources (1)

(3) CONCERN ABOUT CHEMICALS

- Fracking involves dangerous chemicals (3)

- Farmers near fracking sites, concern about chemicals (3)

- Economic benefits are spurious because of health and environmental costs (1)

- Experts expressing concern (radiation, contamination etc.) (8)

- Concern about volume of chemicals (2)

- Personal accounts of consequences of chemical spills (3)

- Fracking chemicals are proprietary (3)

(4) RISK AND REGULATION

- Current regulation is insufficient (12)

\section{ANALYSIS}

The analysis focuses on two sides of a debate that is emerging about fracking, with one side highlighting environmental risks and the other economic benefits (Briggle, 2013). Moreover, drawing on Identity Process Theory, we outline the constructed implications of fracking for identity and social and environmental values (e.g. threat constructions). More specifically, we show how the YouTube videos construct identity threat and/or identity enhancement (from an Identity Process Theory perspective) resulting from the implementation of fracking in order to render the practice socially and psychologically tangible for audiences.

As we shall see, the videos go beyond a binary divide of economic benefits versus environmental costs, especially when they discuss the local, social and personal costs of fracking and its implications for traditional ways of life and values. As Finewood and Stroup (2012: 76) have pointed out, "[d]espite the fact that industrial natural gas development is initiated at the national and global scales, land use decision-making and impacts are felt at the local scale where rural stakeholders (who often utilize diverse, resource based livelihood strategies) must compete for the same land and water resources as fossil fuel developers."

In the following we shall first provide an analysis of discussions of environmental, social and psychological costs as portrayed in videos with a negative tone and then proceed to analyse those videos with a positive tone focusing on economic benefits.

\section{Threats to environmental values}

One of the key sets of arguments is based on the claim that fracking poses unacceptable threats to the environment and to intrinsic environmental values such as the safety and availability of clean air, soil and water. This includes arguments about pollution or contamination below ground, on the surface and in the air - all, it is claimed, caused by fracking operations. As well as these contamination arguments, there are arguments about the destruction of natural beauty, as well as the pressure that fracking operations put on the environment, in terms of the demand for water. This also ties in closely with a further set of arguments about the safety and risks of fracking - the connection being that one of the reasons given for why fracking is unsafe or risky is precisely that the (environmental) costs of accidents is high (of course, there are also independent arguments about costs in terms of health, or that 
"chemicals are bad"). Threats to such intrinsic environmental values in turn symbolise potential threats to the continuity principle of identity, given that phenomena (air, earth and water) which are pervasively valued for their very essence are represented as being susceptible to negative change. Such negative change is attributed to pollution.

Overall, these arguments are anchored in an image of destruction, depletion, pollution and contamination affecting the most common natural "elements" that surround people, namely: air, earth and water (Jaspal and Nerlich, in press a). Tied to this is the image of water catching fire, thus linking the anti-fracking arguments also in the fourth of the classical elements known since Antiquity, namely fire. Fracking, as portrayed in the negative/sensationalist videos, does not only pollute, contaminate or destroy those elements that are purported to support human life, it is portrayed as doing so violently through drilling, fracturing and so on. This then seems to be a direct attack on core environmental values attached to land, soil, water and so on. Such images portray fracking as inherently dangerous to the earth surface and subsurface but also to those who live on it. Tying anti-fracking messages to dominant social constructions of fire, earth, air and water may enable such messages to spread more easily and to frame public perceptions. In short, these messages and framings serve to replace existing, long-standing ways of thinking about intrinsic environmental values with alternative, threatening ways of thinking - the negativity of such messages and framings construct a potential threat to the continuity principle of identity. The following themes deal with these types of messages and framings.

\section{Fracking contaminates groundwater and surrounding land}

Videos generally note two ways in which groundwater can be contaminated: by methane, released by fracking; or by the chemicals used in the fracking process. Methane contamination of water is often illustrated dramatically, by igniting the gas collected from kitchen taps, a much contested but essential part of the movie Gasland. One video advises people not to drink their tap water if they live near fracking sites (yt-44). Other videos note that, geologically, fracking is "highly damaging to rocks and aquifers, although mining companies defend the process as ecologically sound" (yt-27). However, surrounding land is typically thought to be at most risk of contamination by chemical spills or accidents.

There are multiple routes by which contamination is said to occur. One video lists the following possibilities: "surface spills, blowouts, poor cementing jobs, and communication to water zones" (yt-31). Storage pits, used to store some of the fracking fluid once it is removed from the wells, are claimed to be "poorly constructed" and "prone to leaks" (yt-27), another video notes that sites are placed very close to rivers (yt-04 and yt-46). In one documentary video, an interviewee claims that "the groundwater is contaminated from the production, from the drilling from the old pits in this entire area" (yt-23)

Fracking fluid is posing a risk of contamination, because of the amount of fresh water that is used and which must be disposed of, as one documentary video notes, "when the fracturing process is complete a large percentage of that fluid comes back up, so we have purposefully polluted large quantities of fresh water with chemicals that do not belong in the human environment" (yt-04 and yt-46).

Similarly, the same video (but a different interviewee) notes that the transportation of these chemicals to and from fracking sites poses a risk: "the amount of fluid that's running around out there in tanker trucks, literally thousands of tanker trucks is such that one tanker truck going off the road with fracking chemicals in it, 
into a river, would wipe it out." (yt-04 and yt-46)

The acceptable number of accidents is regarded as too large: "one serious environmental concern for every 150 wells drilled to date, you do the math, if we're talking hundreds of thousands of wells, we're doing hundreds or thousands of spills" (yt-04 and yt-46)

Moreover, there are concerns about a radioactivity risk: "the level of radium in the Marcellus [shale] is about 267 times the safe amount, meaning that it will kill you" (yt-04 and yt-46). The argument of radioactive contamination is used as a strong deterrent against the adoption of this gas extraction technology. Conversely, in UK media representations of fracking, the risk of radioactivity is closely linked to the risk of developing cancer as a result of "cancer-causing chemicals" being released into drinking water (Jaspal and Nerlich, in press a).

Videos also include personal descriptions of chemical spills from fracking sites which stress the dangers of fracking to humans as well as to wildlife. An interview with a gas-worker, includes the following description of "day-to-day" activities, which metaphorically highlights the damage to the environment: "I've seen chemicals come out the side, literally out of the side, it looked like the mountain was bleeding" (yt-04 and yt-46). In another interview near a fracking site that had an accidental chemical spill, the landowner states that "it killed the pond, killed the fish, killed everything in the pond: no frogs, no turtles, no nothing. The drinking water in our house has high concentrations of lead" (yt-04 and yt-46). Here the stress is on threats (of violence) to the environment conceptualised as a person (bleeding, killing).

An interview featuring the same person, in a different video, highlights a further consequence of the spill, this time focusing on real people: "I was to move up here in 09 , I was gonna retire; but now my wife won't come and my grandkids don't come" (yt-35). Thus, fracking may pose risks, not only to nature, but also to ways of life. It may threaten intrinsic environmental values, on the one hand, and the continuity principle, on the other. There is a systematic construction of negative change to the groundwater and surrounding land, which are of significant personal and cultural value. Moreover, the high number of accidents claimed to be linked to fracking alludes to a loss of control and competence which is detrimental for selfefficacy - in short, fracking is represented as being out of control which in turn limits individuals' sense of control.

\section{Fracking damages the landscape}

Linked to the 'elementary' argument that fracking destroys the earth and pollutes the environment, another kind of argument found in YouTube videos draws on the notion that fracking operations affect and damage areas of natural beauty, thus posing a more tangible threat to intrinsic environmental, including aesthetic, values. A video about fracking in the Delaware River basin frames the issue of whether fracking should be permitted by first quoting sections from the "Wild and Scenic Rivers Act" and then claiming that the Delaware River "has never been in greater danger" (yt-40). Two other un-narrated videos show slides pointing out fracking sites on aerial or landscape photographs; again, with the implicit point that the presence of these sites is a problem (yt-45, yt-49). And again the destruction of the landscapes spills over to endangering traditional ways of life, thereby jeopardising the continuity principle of identity. Similarly, in a third video, a resident near a fracking site describes his unhappiness with the intrusion and disturbance: "It raises my stress level to a point where I don't want to be here anymore... its changing into an industrial zone" (yt-35). The threat to continuity is inextricably related to place identity (Devine-Wright, 2009; 
Devine-Wright and Howes, 2010) - the individual is represented as being compelled to disidentify with a place that has formerly occupied a position of importance in the self. This is attributed to damage to the landscape and the alleged conversion of the place into "an industrial zone."

\section{Fracking puts added pressure on water resources}

Fracking requires large quantities of water. In one news report video, the reporter investigates fracking operations in Texas, where there has been a drought (in 2011). People believe that fracking has exacerbated the drought problem for both farmers and homeowners: "It pulls the water table down, and with a drought, and as much water as they are using; there will be problems" (yt-38). There was a sense in YouTube videos that added pressure on water resources could result in a loss of competence and control over one's life and environment, potentially jeopardising the self-efficacy principle. In short, fracking was said to create problems which could have irreversible effects for individuals and communities, which could no longer be mitigated.

\section{Natural gas is not a cleaner replacement for oil}

One environmental cost that is mentioned only once in the 50 videos is the role that natural gas plays in energy production. It is claimed that "natural gas burns cleaner than any other fossil fuel, but it is not cleaner in its lifecycle... the lifecycle cost in terms of carbon dioxide emission and methane emission from the development of gas from unnatural sources like shale are at least as "dirty as coal" (yt-04 and yt-46). This counters widespread arguments about "clean energy" related to fracking (see Jaspal and Nerlich, in press b). Interestingly, given the general negativity surrounding fracking in many of the YouTube videos, there is a tendency to safeguard continuity by counteracting potentially incongruent arguments concerning the "cleanliness" of fracking. Thus, the contestation of fracking as a "clean energy" may constitute a means of constructing continuity amid potentially incongruent arguments.

Surprisingly, the issue of climate change is not discussed in this context. This may be explained by the notion that "[w]hen it comes to nature, human societies seem to demand not only objectively claimed matters of fact but also subjectively appreciated facts that matter" (Jasanoff, 2010, p. 250). In short, the videos do not create much of a link between fracking and climate change despite references to "clean" energy. The anti-fracking videos also counter another an even more important argument, namely that fracking brings economic benefits.

\section{Economic benefits are spurious because of health and environmental costs}

One of the few negative videos to explicitly acknowledge the economic benefits of fracking suggest that people sometimes fail to acknowledge the environmental and social costs until it is too late: "the vast majority of people here think it's wonderful. They think there will be jobs, they'll be able to keep their families here, they'll be able to pay for education... that's all good on paper, but when things happen that ruin the value of your property, ruin the health of your family, then that all goes out the window" (yt-04 and yt-46). Here we see the emergence of a strand of concerns regarding social and personal costs associated with fracking, which have the power to threaten the continuity principle of identity given the construction of negative change.

The environmental costs of fracking, which are represented in YouTube videos, construct a threat to the individual and group levels of continuity. On the one hand, the representation of fracking as damaging for the environment and landscape 
constructs a threat to continuity at the individual level, since it entails the need to accept and internalise a negative social reality. Moreover, it is possible that the internalisation of a negative social reality could inhibit a sense of self-esteem on the basis of place identity (Devine-Wright, 2009). In other words, fracking is represented as bringing about negative change to the landscape and to existing lifestyles which can induce a threat to (individual) continuity and self-esteem. This is consistent with research into environmental threat and identity processes (Bonauito, Breakwell and Cano, 1998), which found residents tended to perceive their local and national beaches as less polluted, despite objective evidence of beach pollution in their localities. It was argued that the denial of pollution constituted a means of mitigating threats to individual continuity and self-esteem (derived from perceiving a "clean" unpolluted beach).

On the other hand, fracking is represented as a real threat to humanity due to the alleged risk to human health (most commonly conceived in terms of its alleged links to an increase in cancer risk, see Steingraber et al., 2011). Residents' accounts construct imagery of death and desolateness which further reiterates the risk of harm to human beings and possibly even destruction of life itself. Collectively, these forms of imagery can result in a threat to the group level of continuity - fracking is implicitly constructed as threatening humanity itself. Indeed, threats to group continuity have similarly been observed in media representations of the impending threat of climate change (Jaspal and Nerlich, in press, b).

In the next section, we outline some of the social costs of fracking which are represented in the YouTube clips and continue to consider the threat representations that are encouraged in them.

\section{Threats to human values}

In addition to the perceived threats posed to the environment and intrinsic environmental values, which videos with a negative view of fracking typically emphasise, there is another set of arguments that support the claim that the gas industry imposes significant social costs in areas in which fracking is implemented. The problem is typically linked to the industrialisation of areas that previously did not have any heavy industry, and the negative effect this has on residents' and gas company workers' lives. The videos continue to construct threats to continuity, in particular.

\section{Industrial traffic and lack of existing infrastructure}

A number of videos note the effect of increased heavy truck traffic in areas where fracking is taking place and being developed, especially the disruption and inconvenience it causes to residents of towns near fracking sites. One video features the following comment from a resident of a (previously) small town: "the days sitting out the front of the dinner having a nice conversation are long gone" (yt-04 and yt46). Another video features a local woman who explains that: "the truck traffic unless you experience it is beyond belief... they speed, they sometimes drive down the centre lane" (yt-35). Furthermore, one "protest song" video emphasises the social costs of increased traffic by blaming the trucks for causing delays to ambulances (yt-42). The increased traffic is taken as an indication of a lack of sufficient infrastructure to deal with the growth of the fracking industry in parts of the US - for example, the transport and disposal of fracking chemicals. Collectively, the accounts regarding the social costs of fracking, which are presented in the clips, construct an undesirable change to individuals' lifestyles and social surroundings. This is reflected in accounts 
of disruption and inconvenience caused to people's lives, the sudden inability of residents to interact with each other as they did before, and the unprecedented changes in their environment. Accordingly, fracking is represented as a threat to the social psychological thread connecting past, present and future, that is, individuals' sense of continuity (Chandler et al., 2003).

\section{Fracking causes the industrialisation of small towns}

More generally, the influx of people and industry to rural areas, such as North Dakota, is noted by a number of videos as being disruptive to local residents' lives. One of the news-report videos includes an interview with a resident of a North Dakota town, who claims: "The people here would like things to calm down a little bit" (yt-14). Some videos note the speed with which changes are happening: "In less than a decade the area has become rapidly industrialised, with over 5,000 wells drilled" (yt-23). While others note the magnitude of the changes, for instance, in terms of the population increase: "The population of this North Dakota town has nearly doubled to over 20,000, people from all over the country are flocking to the north west corner of this state" (yt-38). One news report video therefore notes that: "As more money and more people pour into the area, so do more big city problems" (yt-38). Videos also contain interviews with local residents lamenting the development of the gas industry: "It's changing into an industrial zone" (yt-35), and: "our quality of life has deteriorated so greatly. It is the loss of our solitude" (yt-38). In addition, the industrialisation of towns is reported, in many of the videos, to have social costs through unbalancing the local economy: "its hard to make someone work for $\$ 40,000$ or so in the city, when they can get triple that with the oil industry" (yt-14).

In her critical geography research into wind development in Nevada, Phadke (2011) shows how the speed and scale of industrial change have affected rural landscape identities. Similarly, here it appears that many of the YouTube clips converge in their representation of negative change to the local context, despite the potentially positive aspects of industrialisation such as job creation. In residents' accounts there is a desire for "things to calm down a bit," suggesting that the process of industrialisation is evaluated negatively. More specifically, the "doubling" of the population of the North Dakota town is said to have induced "big city problems" formerly unknown to the town and to have created some unbalancing of the economy. On a social level, residents lament the deterioration in the quality of life as a result of fracking. Consequently, here too there is a constructed threat to individuals' sense of continuity over time due to the introduction of negative change in their lives. Yet, there is an implicit threat to self-efficacy in the implementation of fracking because the unbalancing of the economy has decreased economic competence beyond the control of citizens.

\section{Impacts on individual and community health and human values}

In addition to the accounts from residents which are presented in the clips, a further dimension to the social costs of fracking is the effect on the working and lifestyle patterns of gas-workers. Many videos claim that working in the oil fields is migratory, for example, in one interview a worker states: "Its kinda sad, a lot of people come and go. Then the next day their company moves them". In the same video, the worker goes on to note, in a tragic tone, that: "I'm making more now than I would have if I had gone to college. I was going to school for alternative energy; and here I am in the oil field. So much for solar panels" (yt-28). As well as moving a lot, the work itself is irregular. The same news-report interviews the owner of temporary 
housing for gas-workers who explains that: "some guys go out at 2.30 in the morning, some guys at 10.30 in the morning there's never any normal here" (yt-28).

Other news-report videos comment on the skewed gender balance of towns' increased populations and the typical lifestyle. One notes: "The first two days we were here, and we spent a lot of time here, I didn't see a child. I probably saw the male to female ratio of, like, 20 to 1" (yt-14) and then later: "socially, there's not a lot of socialising going on; they're making money and going home" (yt-14). Similarly a worker being interviewed in a news-report says, "the best thing about a man camp ${ }^{1}$ ? I don't know I couldn't really tell you. I can tell you the worst thing, it's a man camp and not a woman camp" (yt-28).

The accounts presented in the clips suggest that fracking introduces inconsistency in the lives of gas workers, impeding any sense of routine. The accounts construct a threat to identity coherence, which is threatening for identity (Jaspal and Cinnirella, 2010). However, like the other social costs of fracking, the absence of socialising, something that the gas workers clearly value, constitutes an example of negative change in their lives. This is also the case for those gas workers who lament the absence of women in their social context. These forms of negative change reflect a threat to individuals' sense of continuity.

\section{Housing gas-workers}

In many of the news-report videos, a prominent aspect of how gas-workers' lives are affected relates to housing. A number of videos explain that in areas where fracking is taking place, there are not enough houses for the influx of workers, "the irony of the Bakken [shale field] is that you can find a job but you can't find a place to live" (yt14). As a consequence, oil companies have provisioned their own housing; a phenomenon that the news-report videos take an interest in "oil companies have built temporary housing, thousands of workers live in so called man camps" (yt-38) and, "essentially what a man camp is a hotel all on one floor. What you're having is bringing a small little city somewhere. Most of the man camps are always located in rural settings" (yt-28). More tragically, there are also interviews with gas-workers who are living in cars: "I've got my bed in my truck, that's basically what it boils down to; all for a job." (yt-14). It is easy to see how the self-esteem and continuity principles may be susceptible to threat in such living conditions - individuals are represented as being unable to derive a positive self-conception on the basis of their living conditions and change is constructed as being negative.

Compared to videos exploring in detail the environmental and social and personal impacts of fracking, those touting its economic benefits are rare.

\section{Economic values}

Videos which are positive about fracking frequently mention the economic value that the fracking industry brings to individuals and communities. Equally, many of the news-report videos highlight the positive economic benefits of the fracking industry. Claims about economic benefits are more consistent than claims about environmental and social costs: the fracking industry creates jobs and boosts local economies. Unlike the previous claims about environmental and social costs, which were anchored in folk knowledge of "elements" and fears about contamination, pollution and

\footnotetext{
${ }^{1}$ A "man camp" is a cluster of communal trailers in an industrial area that accommodates the predominantly male workers. Man camps have become particularly prevalent in fracking sites.
} 
destruction, these arguments are anchored in hopes and fears about money.

\section{Fracking boosts the economy}

The boost to local economies is noted as being largely due to the influx of people and industry into previously small or rural towns. For example, one news-report video notes that the industry has: "transformed the economic landscape: truck traffic, everywhere; construction, everywhere; people, yep, everywhere" and goes on to note that: "the trickle down to the local economy has been dramatic... before the boom this undeveloped land outside of Williston was worth $\$ 15,000$, it recently sold for $£ 200,000$ " (yt-14). The explanatory 'marketing' videos, in addition to describing what fracking involves, often touch on its benefits, too: "it will also create jobs, stimulate the economy" (yt-26) or, if they feature statements from gas-workers or spokespeople, include comments such as: "all the activity, all the jobs out here, wouldn't exist if we couldn't hydraulically fracture these wells" (yt-29).

\section{Fracking creates jobs}

Another news-report makes the observation that "North Dakota boasts the lowest unemployment rate in the country" (yt-38), while others also feature interviews with gas-workers, who hold the view that "back home there's no jobs, you come down here and there's jobs everywhere" (yt-28). Notably, one video features an interview with a truck driver, who has benefited from the fracking industry: "we didn't have to file for bankruptcy, you know, this is the American way. If you can still put your boots on you go to work, and you do it" and later "its people on the ground that made this country great; and North Dakota is full of them" (yt-11).

These clips construct fracking as bolstering identity, primarily through its constructed benefits for the self-efficacy principle of identity. Self-efficacy reflects one's "beliefs in one's capabilities to organize and execute the course of action required to produce given attainments" (Bandura, 1997: 3). By representing fracking as being conducive to economic prosperity and job creation, the clips also construct implementation of the technology as conducive to feelings of competence and control over one's life - it is represented as empowering people to attain their goals and ultimately to lead better lives.

\section{DISCUSSION AND CONCLUSION}

Much research on fracking focuses on the economic and environmental risks and benefits of this new technology, such as "water contamination, seismicity, waste, water and water usage, subsidence, long term fate of fracking fluid, changes in subsurface pressure regime, impact on landscape, fugitive emissions,"iv (Howarth and Ingraffea, 2011). Similarly, the anti-fracking movement tends to emphasise these concerns and to use them as a basis for denigrating fracking (see Jaspal and Nerlich, in press b). The YouTube videos studied here certainly tackle these issues too, but their principal focus lies on the social, personal and psychological concerns raised by fracking, especially threats to intrinsic environmental values and to social and individual identity in terms of identity continuity, self-efficacy and other principles. While the pro- and the anti-fracking lobbies position themselves as speaking for "the people on the ground," their positions tend to focus on the economic and environmental dimensions of fracking.

By contrast, the YouTube videos provide novel insight into the social and psychological dimensions of fracking through the accounts of some of the people affected by fracking in a first-hand manner. The qualitative approach to Identity 
Process Theory provides insight into how the identity principles are conceptualised by individuals themselves (Coyle and Murtagh, 2013). It elucidates not only how intrinsic environmental values may be threatened, but also how the cultural values of continuity, self-efficacy etc may be similarly jeopardised by the implementation of fracking. Although threats to nature and culture are not easily disentangled, the qualitative approach employed in this article does allow for a more fine-grained analysis of threats to nature and cultural values.

In research into wind energy development, there is generally a focus on the aesthetics of "industrializing landscapes," which are linked to negative perceptions of wind farms (Devine-Wright, 2005). In general, people are more likely to support the installation of smaller wind turbines as this is regarded as a means of limiting the negative visual impact of wind energy development. Yet, in the context of fracking, the concerns voiced by laypeople are not only aesthetic, economic and environmental ones. People living with fracking worry about livelihoods, ways of life, and daily life, from housing to traffic to working in all-men working camps. These reflect the social and personal impacts that fracking may have on individuals and communities, as well as the relation between individuals and communities (winners and losers, supporters and sceptics and so on), which are normally sidelined in discussions about scientific evidence of risks or estimations of market values related to fracking. Qualitative research methods are particularly useful in examining the human identity implications of fracking by examining the accounts and constructions offered by community members in a first-hand manner.

It would appear that the human identity implications of fracking may be more complex than the implications of wind energy development, for instance, potentially affecting multiple principles of identity in both positive and negative ways depending upon the position of social actors and broader social representations (Jaspal and Nerlich, in press, a). Fracking may have direct impacts on, and pose threats to, cherished elements of life such as air, water, earth and fire, as well as climate, but most importantly it seems, it may have implications for and pose threats to how people involved in fracking or living near fracking sites lead their daily lives. This can impact one's sense of continuity (Chandler et al., 2003). Yet, fracking may also have positive outcomes for self-efficacy through the constructed benefits for employment and the economy (Bandura, 1997). This article did not set out to discuss how all of the principles may be affected but the qualitative approach allows us to identify how particular principles could be affected in potentially unexpected ways. Thus, the article opens up a debate on the human identity implications that fracking may have. Identity Process Theory (Breakwell, 1986) provides a useful heuristic framework for understanding the forms of social psychological threat (and indeed, enhancement) that are represented as being associated with the implementation of fracking.

Jaspal, Nerlich and Cinnirella (in press) have argued that identity is an important factor in both public understanding of, and public responses to, climate change and mitigation technologies, given that groups and individuals strive to safeguard the important principles that underlie their individual and social identities (i.e. continuity, coherence etc). Moreover, they highlight the importance of finegrained qualitative approaches in understanding the subjective, phenomenological experiences of climate change and mitigation technologies. This article provides some insight into the forms of identity (including individual and social value) threats that are constructed in high-impact YouTube clips on fracking. It shows what kinds of identity threat or enhancement may be constructed in order to either denigrate or promote the technology among the public. 
However, further research is needed. More specifically, the social and psychological consequences of fracking need to be studied, especially in the United States where fracking is as widespread as opposition to fracking (Negro, 2012). The film Gasland began the process of looking at the impact of fracking on communities, homeowner, landowners and gas workers, but more systematic and academic work is needed in the future. So far, it seems, individuals and social systems, have scarcely been studied at all. There is no systematic study of "ecological, cultural, and other non-economic values" in the context of fracking (Finewood and Stroup, 2012: 73). Our small-scale study of YouTube videos shows that there is a pressing need to understand social systems, personal experiences and threats to identity more, in addition to the important research into economic and environmental systems. There is a long tradition of studying issues around the regulation of human and environmental risks, whereas thinking about human values in this context is as yet rare, although this might be changing within the emerging landscape of "responsible innovation" (Owen et al., 2013).

In this article, we decided to exploit the social constructivist potential in Identity Process Theory to examine how human and environmental values and identity principles are constructed as being threatened by the practice of fracking in YouTube videos. This is important because constructions of threat may in turn feed into public understanding of fracking (Jaspal, Nerlich and Cinnirella, in press). Indeed, Identity Process Theory has long been associated with qualitative research methods, partly because of its flexibility in application and its heuristic utility (Coyle and Murtagh, 2013). In future research using the theory, it would be useful to examine the perceived impact of fracking for identity among affected individuals using indepth qualitative interview and quantitative survey-based methods. While this research highlights which principles may be susceptible to influence in the context of fracking, it is descriptive and says little about the potential interactions between the identity principles. It is, for instance, unclear whether the threat to continuity, which seems to be associated with threats to intrinsic environment values, would be tolerable given the obvious potential that the employment and economic opportunities afforded by fracking can have for the self-efficacy principle of identity. Social psychologists can make an important contribution to this area. Moreover, it would be useful to examine the impact for particular identities, particularly place identity, which seems to be affected by fracking. This would complement existing research into place identity which has been fruitfully conducted in the context of wind energy and NIMBYism, for instance (Devine-Wright, 2009; Devine-Wright and Howes, 2010). Such an integrative programme of research would shed further light on the human dimension of fracking which unfortunately remains under-explored.

\section{REFERENCES}

Bandura, A. 1997. Self-efficacy: The Exercise of Control. New York: Freeman.

Bonauito, M., Breakwell, G. M. and Cano, I. 1998. 'Identity processes and environmental threat: the effects of nationalism and local identity upon perception of beach pollution'. Journal of Community and Applied Social Psychology 6(3): 157175.

Braun, V. and Clarke, V. 2006. 'Using thematic analysis in psychology'. Qualitative Research in Psychology 3: 77-101. 
Breakwell G.M. 1986. Coping with Threatened Identities. London: Methuen.

Breakwell, G.M. 2010a. 'Models of risk construction: some applications to climate change'. Wiley Interdisciplinary Reviews: Climate Change 1(6): 765-907.

Breakwell, G. M. 2010b. 'Resisting Representations and Identity Processes'. Papers in Social Representations 19: 6.1-6.11.

Briggle, A. 2013. 'Duck, rabbit, gas well: A Gestalt theory of the fracking debate'. Science Progress (blog), 17 January: http://scienceprogress.org/2013/01/duck-rabbitgas-well/

Callicott, B. 1989. In Defense of the Land Ethic: Essays in Environmental Philosophy. Albany, NY: State University Press of New York Press.

Chandler, M. J., Lalonde, C. E., Sokol, B. and Hallett, D. 2003. 'Personal persistence, identity development, and suicide: a study of native and non-native North American adolescents'. Monographs of the Society for Research in Child Development 68(2): Serial No.273.

Coyle, A. and Murtagh, N. 2013. 'Qualitative approaches to research using Identity Process Theory'. In R. Jaspal and G.M Breakwell (eds.), Identity Process Theory: Identity, Social Action and Social Change. Cambridge: Cambridge University Press.

Devine-Wright, P. 2005. Beyond NIMBYism: Towards an integrated framework for understanding public perceptions of wind energy. Wind Energy 8: 125-139

Devine-Wright, P. 2009. 'Rethinking NIMBYism: The role of place attachment and place identity in explaining place-protective action'. Journal of Community and Applied Social Psychology 19(6): 426-441.

Devine-Wright, P. and Howes, Y. 2010. 'Disruptions To Place Attachment And The Protection Of Restorative Environments: A wind energy case study'. Journal of Environmental Psychology 30(1): 271-290.

Dixon, J., Durrheim, K. and Di Masso, A. 2013. 'Places, identities and geopolitical change: Exploring the strengths and limits of Identity Process Theory'. In R. Jaspal and G.M Breakwell (eds.), Identity Process Theory: Identity, Social Action and Social Change. Cambridge: Cambridge University Press.

Elliot, R. 1992. 'Intrinsic value, environmental obligation, and naturalness'. The Monist 75: 138-160.

Engelder, T. 2011. 'Should fracking stop? No, it's too valuable'. Nature 447: 271-75.

ESRC http://www.esrc.ac.uk/impacts-and-findings/featurescasestudies/features/20493/Fracking_and_public_dialogue_.aspx

Finewood, M.H. and Stroup, L.J. 2012. 'Fracking and the Neoliberalization of the Hydro-Social Cycle in Pennsylvania's Marcellus Shale'. Journal of Contemporary 
Water Research and Education 147: 72-79.

Fox, J. 2010. Gasland. New Video Group.

Freeman B. and Chapman S. 2007. Is "YouTube" telling or selling you something? Tobacco content on the YouTube video-sharing website. Tobacco Control 16(3): 207-10.

Guggenheim, D. 2006. An Inconvenient Truth. Lawrence Bender Productions.

Howarth, R.W. and Ingraffea, A. 2011. 'Should fracking stop? Yes, it's too high risk'. Nature 477: 271-75.

Jasanoff, S. 2010. 'A New Climate For Society'. Theory, Culture and Society 27(2-3): 233-253

Jaspal, R. 2013. 'Social psychological debates about identity'. In R. Jaspal and G.M Breakwell (eds.), Identity Process Theory: Identity, Social Action and Social Change. Cambridge: Cambridge University Press.

Jaspal, R. and Cinnirella, M. 2010. 'Coping with potentially incompatible identities: accounts of religious, ethnic and sexual identities from British Pakistani men who identify as Muslim and gay'. British Journal of Social Psychology 49(4): 849-870.

Jaspal, R., Nerlich, B. and Cinnirella, M. in press. 'Human responses to climate change: Social representation, identity and socio-psychological action'.

Environmental Communication: A Journal of Nature and Culture.

Jaspal, R. and Nerlich, B. in press a. 'Fracking in the UK media: Threat dynamics in an unfolding debate'. Public Understanding of Science.

Jaspal, R. and Nerlich, B. in press b. 'When climate science became climate politics: British media representations of climate change in 1988'. Public Understanding of Science. Available first online:

http://pus.sagepub.com/content/early/2012/04/10/0963662512440219.abstract

Jaspal, R., Nerlich, B. and Koteyko, N. 2013. 'Contesting Science by Appealing to its Norms: Readers Discuss Climate Science in The Daily Mail'. Science Communication 35(3):

Keelan J, Pavri-Garcia V, Tomlinson G, Wilson K., 2007. 'YouTube as a source of information on immunization: a content analysis'. JAMA 298(21): 2482-4.

Lashley, M. 2012. 'Lip dubbing on YouTube: Participatory culture and cultural globalization'. Transformative Works and Cultures 11: doi:10.3983/twc.2012.0408.

Lyons, E. 1996. 'Coping with social change: processes of social memory in the reconstruction of identities'. In G.M. Breakwell \& E. Lyons (eds.), Changing European Identities: Social Psychological Analyses of Social Change, pp.3140.Oxford: Butterworth-Heinemann. 
Mooney, C. 2011. 'The truth about fracking'. Scientific American 305: 80-85

Negro, E.E. 2012. 'Fracking wars: Federal, state and local conflicts over the regulation of natural gas activities'. Zoning and Planning Law Report 35(2): 1-13.

Nerlich, B. 2010. “'Climategate': Paradoxical Metaphors and Political Paralysis'. Environmental Values 19(4): 419-442.

Nerlich, B. and Jaspal, R. in press. 'Images of extreme weather: Symbolising human responses to climate change'. Science as Culture.

O’Hara, S. Humphrey, M., Jaspal, R., Nerlich, B., and Poberezshkaya, M. 2012. Shale gas extraction in the UK: What people think:

http://www.scribd.com/doc/98974352/Public-Perceptions-of-Shale-Gas-in-the-UK-7

O’Hara, S. Humphrey, M., Jaspal, R., Nerlich, B., and Poberezshkaya, M. 2013. Public perception of shale gas extraction in the UK: How people's views are changing: http://ground-gassolutions.co.uk/wpcontent/uploads/2013/03/Nottm_PublicPerceptionsShaleGasUK_Mar2013.pdf

Owen, R., Bessant, J., Heintz, M. (eds.) 2013. Responsible Innovation: Managing the responsible innovation of science and innovation in society. Chisester: John Wiley and Sons.

Pandey A, Patni N, Singh M, Sood A, Singh G. 2010. 'YouTube as a source of information on the H1N1 influenza pandemic'. American Journal of Preventive Medicine 38(3): e1-e3.

Phadke, R. 2011. 'Resisting and Reconciling Big Wind: Middle Landscape Politics in the New American West'. Antipode 43(3): 754-776.

Porter, A. J. and Hellsten, I. R. in press. 'Investigating social media responses to complex social problems using a multi-determinant framework: The case of climategate on YouTube'. Journal of Computer Mediated Communication.

The Royal Society and The Royal Academy of Engineering 2012. 'Shale gas extraction in the UK: a review of hydraulic fracturing'. June 2012:

royalsociety.org/policy/projects/shale-gas-extraction and raeng.org.uk/shale

Schwartz, S. H. 1992. 'Universals in the content and structure of values: Theory and empirical tests in 20 countries'. In M. Zanna (ed.), Advances in experimental social psychology, pp. 1-65. New York: Academic Press.

Slezak, M. 2012. 'Methane leaks suggest fracking benefits exaggerated'. New Scientist, 21 November, 2892 http://www.newscientist.com/article/dn22521-methaneleaks-suggest-fracking-benefits-

exaggerated.html?goback=.gde_67258_member_188195707

Steingraber, S. and others 2011. 'Letter to the Honorable Andrew M. Cuomo, 
Governor of New York State'. December 12, 2011. Available at:

http://steingraber.com/wordpress/wp-content/uploads/CancerFrackingDec12.pdf

Stiles, W.B. 1999. 'Evaluating qualitative research', Evidence-based Mental Health 2: 99-101.

Van Sant, G. 2012. Promised Land. Participant media.

$\begin{array}{ll}\text { i } & \text { https://www.dur.ac.uk/refine/ } \\ \text { ii } & \text { http://www.gaslandthemovie.com/. } \\ \text { iii } & \text { http://frack-off.org.uk/fracking-hell/watch-the-film/ } \\ \text { iv } & \text { https://www.dur.ac.uk/refine/ }\end{array}$

